Published in final edited form as:

Org Lett. 2016 September 16; 18(18): 4466-4469. doi:10.1021/acs.orglett.6b01938.

\title{
1,3-Dipolar Cycloaddition with Diazo Groups: Noncovalent Interactions Overwhelm Strain
}

\author{
Brian Gold ${ }^{\# \dagger}$, Matthew R. Aronoff ${ }^{\# \dagger}$, and Ronald T. Raines ${ }^{\star}, \dagger, \ddagger$ \\ tDepartment of Chemistry, University of Wisconsin-Madison, Madison, Wisconsin, 53706, United \\ States \\ ‡Department of Biochemistry, University of Wisconsin-Madison, Madison, Wisconsin, 53706, \\ United States \\ \# These authors contributed equally to this work.
}

\begin{abstract}
Like azides, diazoacetamides undergo 1,3-dipolar cycloadditions with oxanorbornadienes (OND) in a reaction that is accelerated by the relief of strain in the transition state. The cycloaddition of a diazoacetamide with unstrained ethyl 4,4,4-trifluoro-2-butynoate is, however, 35-fold faster than with the analogous OND because of favorable interactions with the fluoro groups. Its rate constant ( $k=0.53 \mathrm{M}^{-1} \mathrm{~s}^{-1}$ in methanol) is comparable to those of strain-promoted azide-cyclooctyne cycloadditions.
\end{abstract}

\section{Graphical abstract}<smiles></smiles>
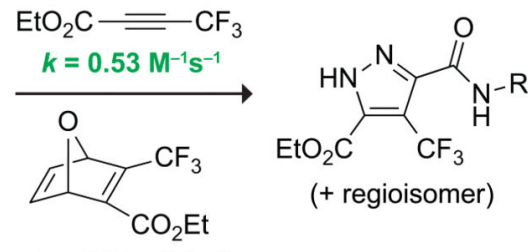

$$
k=0.015 \mathrm{M}^{-1} \mathrm{~s}^{-1}
$$

The Huisgen 1,3-dipolar cycloaddition dominates the landscape of reactions that are chemoselective in biological contexts. ${ }^{1}$ Although the copper-catalyzed azide-alkyne cycloaddition $(\mathrm{CuAAC})^{2}$ and the strain-promoted azide-alkyne cycloaddition (SPAAC) ${ }^{1 \mathrm{a}}$ fulfill many criteria of an ideal "click" reaction, ${ }^{2}$ the desire for increased reactivity and selectivity in non-catalyzed reactions remains strong. ${ }^{3}$

Recently, we demonstrated the use of a stabilized diazo group as a chemical reporter. ${ }^{1 \mathrm{k}, 4,5}$ Despite significant conjugative stabilization, diazoacetamides are primed for rapid normalelectron-demand 1,3-dipolar cycloadditions, and show reaction rates with strained alkynes

*Corresponding Author, rtraines@wisc.edu.

Supporting Information. Synthetic methods and analytical data along with additional computational data, Cartesian coordinates, energies, and imaginary frequencies (for TSs). This material is available free of charge via the Internet at http://pubs.acs.org. 
that surpass those of azides. ${ }^{6}$ Moreover, diazoacetamides endure cellular metabolism, and provide chemoselectivity in the presence of terminal alkynes, a feature unobtainable with an azido moiety. ${ }^{1 \mathrm{k}}$ Still, overlapping reactivity with azido groups does not allow for selective reactivity of diazo groups in an SPAAC. We have found, however, that removing strain and tuning the LUMOs of the dipolarophile can provide diazo-selective reactivity. ${ }^{7}$ In addition, cycloaddition rates with a, $\beta$-unsaturated carbonyl compounds are increased by incorporating electron-withdrawing substituents. ${ }^{8}$

We sought to incorporate strain while retaining electronic tunability as a primary design feature. These attributes are enabled in the bicyclic oxanorbornadiene (OND) scaffold (Scheme 1). Electron-deficient ONDs are effective dipolarophiles in reactions with azides, displaying increased reactivity relative to their linear precursors. ${ }^{9}$ This increase is a consequence of the relief of ring-strain in the transition state (TS), along with a lower LUMO energy of the bicyclic alkene compared to that of an alkynyl $\pi$-bond. ${ }^{10}$ Their facile preparation from common starting materials and opportunity for alkenyl substitution make ONDs attractive in comparison to synthetically recalcitrant cyclooctynes. Moreover, the reactions of ONDs with nucleophilic species are rapid enough for numerous applications, ${ }^{11}$ and diazo groups are more nucleophilic than are azido groups. ${ }^{1 \mathrm{j}, 6}$ Accordingly, we explored the reactivity of ONDs shown previously to undergo 1,3-dipolar cycloadditions with azides. ${ }^{9}$

We found that, like azide 2 , diazoacetamide $1(\mathrm{R}=\mathrm{Bn})$ undergoes 1,3-dipolar cycloadditions with OND 4 followed by a retro-Diels-Alder reaction to eliminate furan (Scheme 1). The resulting pyrazole product is identical to that formed upon reaction with analogous alkyne $\mathbf{3}$. Unlike with azides, ${ }^{9}$ however, we found that diazoacetamide $1(R=B n)$ does not react with the unsubstituted alkenyl group of ONDs $\mathbf{4 a}$ and $\mathbf{4 b}$.

Cycloaddition reactions of an azido group with ONDs are known to be $\sim 5$-fold faster than are those with analogous alkynes. ${ }^{9 a}$ Accordingly, we determined rate constants for the cycloadditions of diazoacetamide $\mathbf{1}(\mathrm{R}=\mathrm{Bn})$ with $\mathrm{ONDs} \mathbf{4 a}\left(\mathrm{R}^{1}=\mathrm{CO}_{2} \mathrm{Et}, \mathrm{R}^{2}=\mathrm{CF}_{3}\right)$ and $\mathbf{4 b}$ $\left(\mathrm{R}^{1}=\mathrm{R}^{2}=\mathrm{CO}_{2} \mathrm{Me}\right.$ ) and analogous alkynes $\mathbf{3 a}$ and $\mathbf{3 b}$ (Figure $\left.\mathrm{S} 1\right)$. We found the rate constants for the cycloaddition of diazoacetamide $\mathbf{1}(\mathrm{R}=\mathrm{Bn})$ with ONDs $\mathbf{4 a}$ and $\mathbf{4 b}$ (Table 1) to be $10^{2}$-fold faster than those of azides with ONDs. ${ }^{9 a}$ Moreover, the diazoacetamideOND rate constants are comparable to those of known SPAACs. ${ }^{3}$ The incorporation of strain into OND $\mathbf{4 b}$ increases the rate constant by twofold relative to the reaction with alkyne $\mathbf{3 b}$, a slightly smaller effect than observed in the analogous reactions of azides. ${ }^{9 a}$

The cycloadditions of diazoacetamide $\mathbf{1}$ with alkyne $\mathbf{3 a}$ and analogous OND $4 \mathbf{a}$ were dichotomous with those of azides. ${ }^{9 a}$ Rather than a modest increase in the reaction rate with an OND, ${ }^{9 a}$ we observed the reaction rate of diazoacetamide 1 with OND $4 \mathbf{a}$ to be $1 / 35^{\text {th }}$ that with alkyne 3a. Moreover, the reaction rate of diazoacetamide $\mathbf{1}$ with alkyne 3a is comparable to that of the fastest of reported SPAACs, ${ }^{1 \mathrm{f}, 12}$ and approaches that of the diazoacetamide-DIBAC cycloaddition. ${ }^{1 \mathrm{k}}$ This result was unexpected, as the lower LUMO of alkenes relative to alkynes and the strain imposed by the OND framework led us to anticipate the opposite trend in reactivity. Accordingly, we pursued a computational analysis to better understand the surprising reactivity of alkyne $\mathbf{3 a}$.

Org Lett. Author manuscript; available in PMC 2016 December 09. 
Calculated activation barriers for the cycloadditions of both alkynes and ONDs (Figure 1) correlate with their relative reactivity (Table 1). The 1,3-dipolar cycloaddition should be the rate-determining step in the cycloadditions with ONDs (Figure S2). Based on $\Delta E^{\leftarrow}$ values (Table 2), the origins of the increased reactivity of alkyne 3a are not immediately apparent. Enthalpic contributions suggest that OND 4a should react faster than alkyne 3a (Table S1). FMO energies and the increased strain of bicyclic systems ${ }^{13}$ relative to alkynes also predict a faster rate for the OND. To understand the increased reactivity of alkyne $\mathbf{3 a}$, we turned to the distortion/interaction analysis developed by Ess and Houk (Table 2). ${ }^{14,15}$ In this approach, the overall reaction barrier can be understood as the sum of the free energy required to distort isolated reactants to transition state (TS) geometries and the free energy gained when these distorted reactants interact in the TS: ${ }^{15 a}$

$$
\Delta G^{\ddagger}=\Delta G_{\text {dist }}{ }^{\ddagger}+\Delta G_{\text {int }}{ }^{\ddagger}
$$

The origins of increased reactivity can be understood when free energies of distortion and interaction are taken into account (Table 2). The difference in total distortion free energy between the alkyne and OND TSs $\left(\Delta \Delta G_{\text {dist }}^{\natural}<1 \mathrm{kcal} / \mathrm{mol}\right.$ for 1-3a TS and 1-4a TS), is much less than the difference in total distortion energy $\left(\Delta \Delta E^{\ddagger}\right.$ dist $=1.7 \mathrm{kcal} / \mathrm{mol}$ for $1-\mathbf{3 a}$ TS and 1-4a TS; Figure S3), allowing interactions to dictate the observed reactivity ( $\Delta \Delta G_{\text {int }}=$ $1.4 \mathrm{kcal} / \mathrm{mol}$ versus $\Delta \Delta E^{\dagger}$ int $=0.2 \mathrm{kcal} / \mathrm{mol}$ for $\mathbf{1 - 3 a}$ TS and $\left.\mathbf{1 - 4 a} \mathbf{~ T S}\right)$.

In agreement with FMO energies, the distortion energies of ONDs $\mathbf{4 a}$ and $\mathbf{4 b}$ are significantly lower than are those of alkynes $\mathbf{3 a}$ and $\mathbf{3 b} .{ }^{16}$ Interestingly, the distortion energy of fluorinated OND $\mathbf{4 a}$ is much larger than is that of bis-esterified OND $\mathbf{4 b}$ (8.1 versus 6.4 $\mathrm{kcal} / \mathrm{mol}$ ). This increase appears to be due to a slightly smaller dihedral angle of the alkene in the starting geometry of $\mathbf{4 b}$ along with increased steric crowding of electron-rich substituents in $\mathbf{4 a}$ (Figure 1). The closest $\mathrm{O} \cdots \mathrm{O}$ distance decreases by $0.07 \AA$ from the starting material to the TS geometry in $\mathbf{4 b}(2.88$ to $2.81 \AA$ ), whereas the closest $\mathrm{O} \cdots \mathrm{F}$ distance decreases by $0.12 \AA$ in $\mathbf{4 a}(2.88$ to $2.76 \AA$ ).

In alkyne 3a, which avoids deleterious steric interactions, fluorination facilitates bending, leading to decreased distortion energies. ${ }^{\mathrm{h}}$ In addition, large interaction energies result from hyperconjugative assistance to the nascent bonds or hydrogen-bonding interactions (or both), depending on the regioisomer of the TS (Figure S4). Analogous effects of propargylic fluorination on alkyne bending and interaction energies have been reported previously during cycloadditions with azides ${ }^{1 \mathrm{~h}, \mathrm{j}}$ and diazo compounds. ${ }^{8}$

Lowered distortion energies for diazoacetamide $\mathbf{1}$ in reactions with alkynes $\mathbf{3 a}$ and $\mathbf{3 b}$ (relative to reactions with ONDs $\mathbf{4 a}$ and $\mathbf{4 b}$ ) and shorter incipient $\mathrm{C}-\mathrm{C}$ bonds result in a highly asynchronous TS (Figure 1). The result is unidirectional charge-transfer amplified by propargylic fluoro groups in the reaction of alkyne 3a. The charge-transfer creates a more polar TS and larger solvent effects (Table 2) ${ }^{6,17}$ Only with alkyne 3a is the free energy of activation lower in solution than in the gas phase (Figure S5), suggesting that fluorine induces a more favorable $\Delta S^{\dagger}$ in polar media. 


\section{Conclusions}

We have discovered an unexpectedly large effect of propargylic fluorination on 1,3-dipolar cycloadditions with diazoacetamides. These effects render the reaction with alkyne $\mathbf{3 a}$ to be much faster than that with an OND having analogous substitution and comparable in rate to the fastest known SPAACs. Others have noted that strain-relief is the most significant design principle for increasing the rate of azide-alkyne cycloadditions. ${ }^{19}$ In particular, alkyne bending decreases the HOMO-LUMO gap ${ }^{1 \mathrm{j}}$ - a scenario that is optimal for azido dipoles, which are substantially more ambiphilic than are diazo dipoles. ${ }^{12 \mathrm{~b}}$ In essence, strain provides the opportunity to increase the donor and acceptor properties of the alkyne $\pi$-bond simultaneously, leading to cycloadditions that can be more synchronous than those of linear alkynes.

In comparison to their azido congeners, diazo dipoles are much more nucleophilic., 6,7 Although strain-relief can increase cycloaddition rates, ${ }^{1 \mathrm{k}, 4}$ a strong preference for electrondeficient dipolarophiles renders the diazo group much more sensitive to substituent effects, obviating strain-relief as a sine qua non for rapid reaction. ${ }^{20}$ This difference is advantageous in polar solvents (like water), where highly asynchronous TSs can lead to large rate enhancements. Accordingly, diazo groups are highly tunable moieties of broad potential utility in chemical biology.

\section{Supplementary Material}

Refer to Web version on PubMed Central for supplementary material.

\section{ACKNOWLEDGMENT}

This work was supported by Grant R01 GM044783 (NIH) and made use of the National Magnetic Resonance Facility at Madison, which is supported by Grant P41 GM103399 (NIH). Computational resources were supported in part by Grant CHE-0840494 (NSF).

\section{REFERENCES}

(1) (a). Agard NJ, Prescher JA, Bertozzi CR. J. Am. Chem. Soc. 2004; 126:15046-15047. [PubMed: 15547999] (b) Baskin JM, Prescher JA, Laughlin ST, Agard NJ, Chang PV, Miller IA, Lo A, Codelli JA, Bertozzi CR. Proc. Natl. Acad. Sci. USA. 2007; 104:16793-16797. [PubMed: 17942682] (c) Ning X, Guo J, Wolfert MA, Boons G-J. Angew. Chem., Int. Ed. 2008; 47:22532255.(d) Poloukhtine AA, Mbua NE, Wolfert MA, Boons G-J, Popik VV. J. Am. Chem. Soc. 2009; 131:15769-15776. [PubMed: 19860481] (e) Debets MF, van Berkel SS, Schoffelen S, Rutjes FPJT, van Hest JCM, van Delft FL. Chem. Commun. 2010; 46:97-99.(f) Jewett JC, Sletten EM, Bertozzi CR. J. Am. Chem. Soc. 2010; 132:3688-3690. [PubMed: 20187640] (g) Dommerholt J, Schmidt S, Temming R, Hendriks LJA, Rutjes FPJT, van Hest JCM, Lefeber DJ, Friedl P, van Delft FL. Angew. Chem., Int. Ed. 2010; 49:9422-9425.(h) Gold B, Shevchenko NE, Bonus N, Dudley GB, Alabugin IV. J. Org. Chem. 2012; 77:75-89. [PubMed: 22077877] (i) Varga BR, Kállay M, Hegyi K, Béni S, Kele P. Chem. Eur. J. 2012; 18:822-828. [PubMed: 22190419] (j) Gold B, Dudley GB, Alabugin IV. J. Am. Chem. Soc. 2013; 135:1558-1569. [PubMed: 23272641] (k) Andersen KA, Aronoff MR, McGrath NA, Raines RT. J. Am. Chem. Soc. 2015; 137:2412-2415. [PubMed: 25658416]

(2). Kolb HC, Finn MG, Sharpless KB. Angew. Chem., Int. Ed. 2001; 40:2004-2021. 
(3) (a). Debets MF, van Berkel SS, Dommerholt J, Dirks AJ, Rutjes FPJT, van Delft FL. Acc. Chem. Res. 2011; 44:805-815. [PubMed: 21766804] (b) Patterson DM, Nazarova LA, Prescher JA. ACS Chem. Biol. 2014; 9:592-605. [PubMed: 24437719]

(4). McGrath NA, Raines RT. Chem. Sci. 2012; 3:3237-3240. [PubMed: 23227302]

(5) (a). Caution! Unstabilized diazo compounds (e.g., diazomethane) are highly toxic and explosively reactive; their use should never be attempted in the context of chemical biology. See: Lewinn EB. Am. J. Med. Sci. 1949; 218:556-562. [PubMed: 15392072] de Boer TJ, Backer HJ. Org. Syn. 1956; 36:16-18. Schoental R. Nature. 1960; 188:420-421. [PubMed: 13748420] Lewis CE. J. Occup. Environ. Med. 1964; 6:91-92.

(6). Gold B, Aronoff MR, Raines RT. J. Org. Chem. 2016; 81:5998-6006. [PubMed: 27332711]

(7). Aronoff MR, Gold B, Raines RT. Org. Lett. 2016; 18:1538-1541. [PubMed: 26981746]

(8). Aronoff MR, Gold B, Raines RT. Tetrahedron Lett. 2016; 57:2347-2350. [PubMed: 27909348]

(9) (a). van Berkel SS, Dirks AJ, Debets MF, van Delft FL, Cornelissen JJLM, Nolte RJM, Rutjes FPJT. ChemBioChem. 2007; 8:1504-1508. [PubMed: 17631666] (b) van Berkel SS, Dirks AJ, Meeuwissen SA, Pingen DLL, Boerman OC, Laverman P, van Delft FL, Cornelissen JJLM, Rutjes FPJT. ChemBioChem. 2008; 9:1805-1815. [PubMed: 18623291]

(10). Alabugin IV, Gold B. J. Org. Chem. 2013; 78:7777-7784. [PubMed: 23829276]

(11) (a). Hong V, Kislukhin AA, Finn MG. J. Am. Chem. Soc. 2009; 131:9986-9994. [PubMed: 19621956] (b) Kislukhin AA, Higginson CJ, Hong VP, Finn MG. J. Am. Chem. Soc. 2012; 134:6491-6497. [PubMed: 22455380]

(12) (a). Gordon CG, Mackey JL, Jewett JC, Sletten EM, Houk KN, Bertozzi CR. J. Am. Chem. Soc. 2012; 134:9199-9208. [PubMed: 22553995] (b) Dommerholt J, van Rooijen O, Borrmann A, Guerra CF, Bickelhaupt FM, van Delft FL. Nat. Commun. 2014; 5:5378. [PubMed: 25382411]

(13). Lopez SA, Houk KN. J. Org. Chem. 2013; 78:1778-1783. [PubMed: 22764840]

(14). Ess DH, Houk KN. J. Am. Chem. Soc. 2008; 130:10187-10198. [PubMed: 18613669]

(15). For a tutorial review of the distortion/interaction model (which is also known as the activation strain model), see: Fernández I, Bickelhaupt FM. Chem. Soc. Rev. 2014; 43:4953-4967. [PubMed: 24699791] Wolters LP, Bickelhaupt FM. WIREs Comput. Mol. Sci. 2015; 5:324-343.

(16). Liu F, Liang Y, Houk KN. J. Am. Chem. Soc. 2014; 136:11483-11493. [PubMed: 25041719]

(17) (a). Breslow R. Acc. Chem. Res. 1991; 24:159-164.(b) Meijer A, Otto S, Engberts JBFN. J. Org. Chem. 1998; 63:8989-8994.(c) Chandrasekhar J, Shariffskul S, Jorgensen WL. J. Phys. Chem. B. 2002; 106:8078-8085.(d) Narayan S, Muldoon J, Finn MG, Fokin VV, Kolb HC, Sharpless KB. Angew. Chem., Int. Ed. 2005; 44:3275-3279.(e) Ess DH, Jones GO, Houk KN. Adv. Synth. Catal. 2006; 348:2337-2361.(f) Jung Y, Marcus RA. J. Am. Chem. Soc. 2007; 129:5492-5502. [PubMed: 17388592]

(18). Glendening, ED.; Badenhoop, JK.; Reed, AE.; Carpenter, JE.; Bohmann, JA.; Morales, CM.; Landis, CR.; Weinhold, F. NBO 6.0. Theoretical Chemistry Institute, University of Wisconsin; Madison, WI: 2013.

(19). Sletten EM, de Almeida G, Bertozzi CR. Org. Lett. 2014; 16:1634-1637. [PubMed: 24588780]

(20). The incorporation of highly electronegative substituents could, however, lead to undesirable side reactions, such as conjugate addition (ref. 11a).

Org Lett. Author manuscript; available in PMC 2016 December 09. 

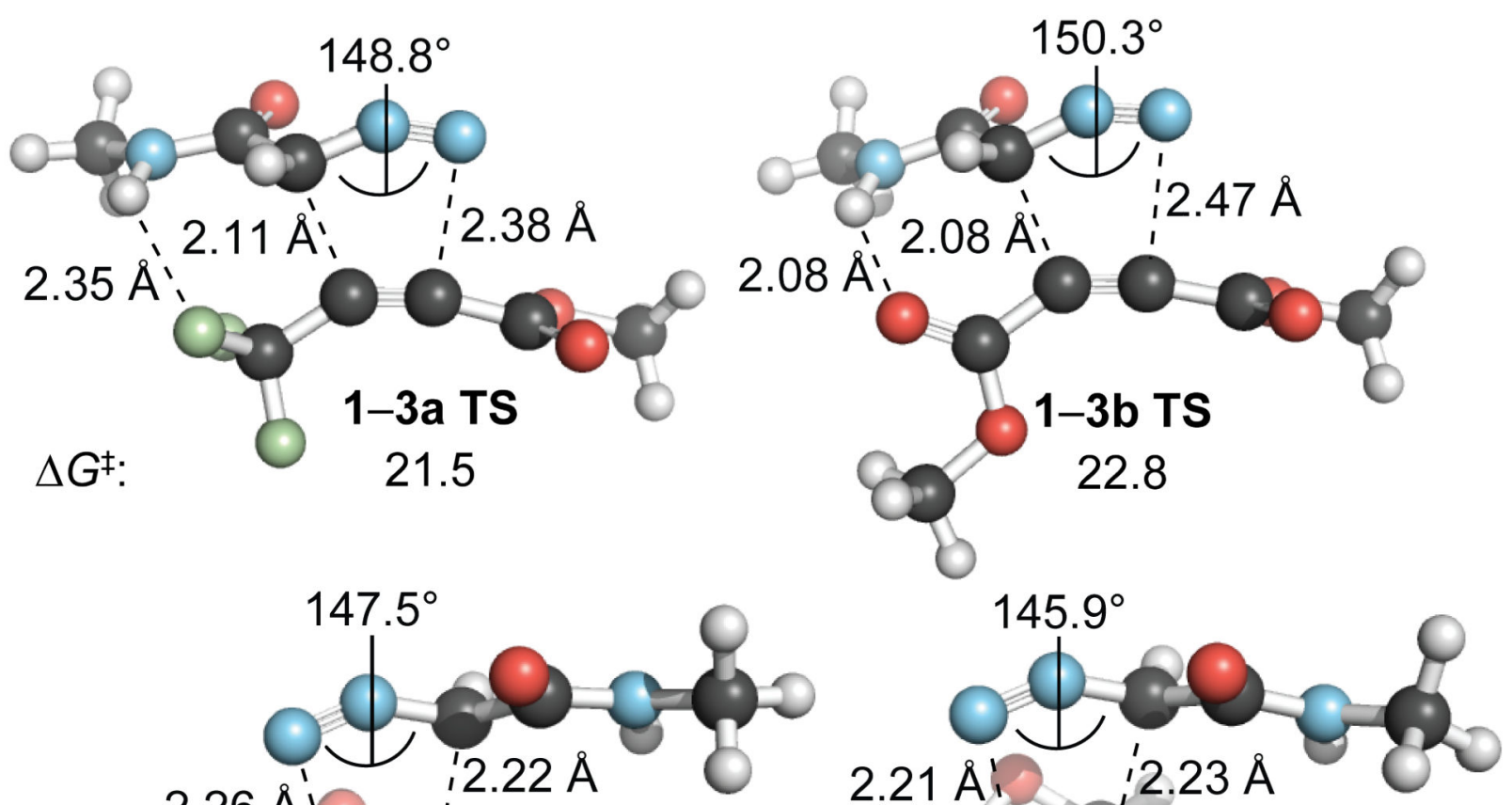

$\Delta G^{\ddagger}$

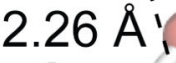

$2.21 \AA$ '2.23 A

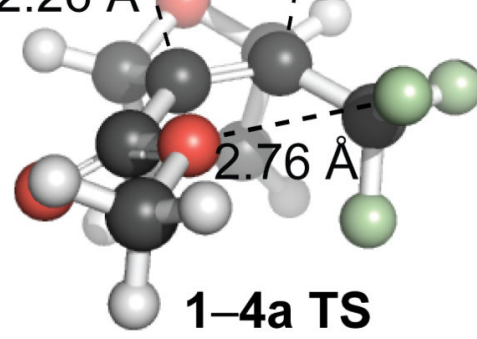

22.1

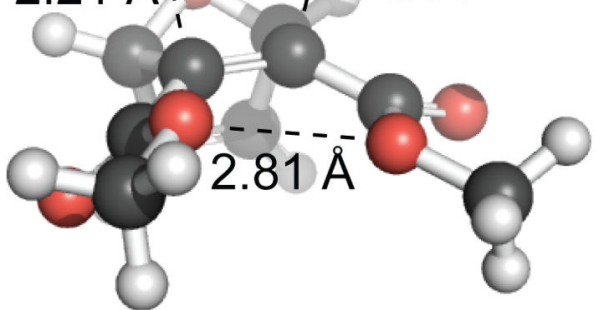

1-4b TS

22.5

Figure 1.

Optimized transition-state geometries for the cycloaddition of diazoacetamide $\mathbf{1}(\mathrm{R}=\mathrm{Me})$ with alkynes $\mathbf{3 a}$ and $\mathbf{3 b}$ and with ONDs $\mathbf{4 a}$ and $\mathbf{4 b}$ as calculated at the M06-2X/ $6-31+\mathrm{G}(2 \mathrm{~d}, \mathrm{p})$ level of theory. Free energies ( $\mathrm{kcal} / \mathrm{mol})$ include solvation corrections $(\mathrm{MeOH})$ on gas-phase geometries with the IEFPCM model (radii = UFF). 


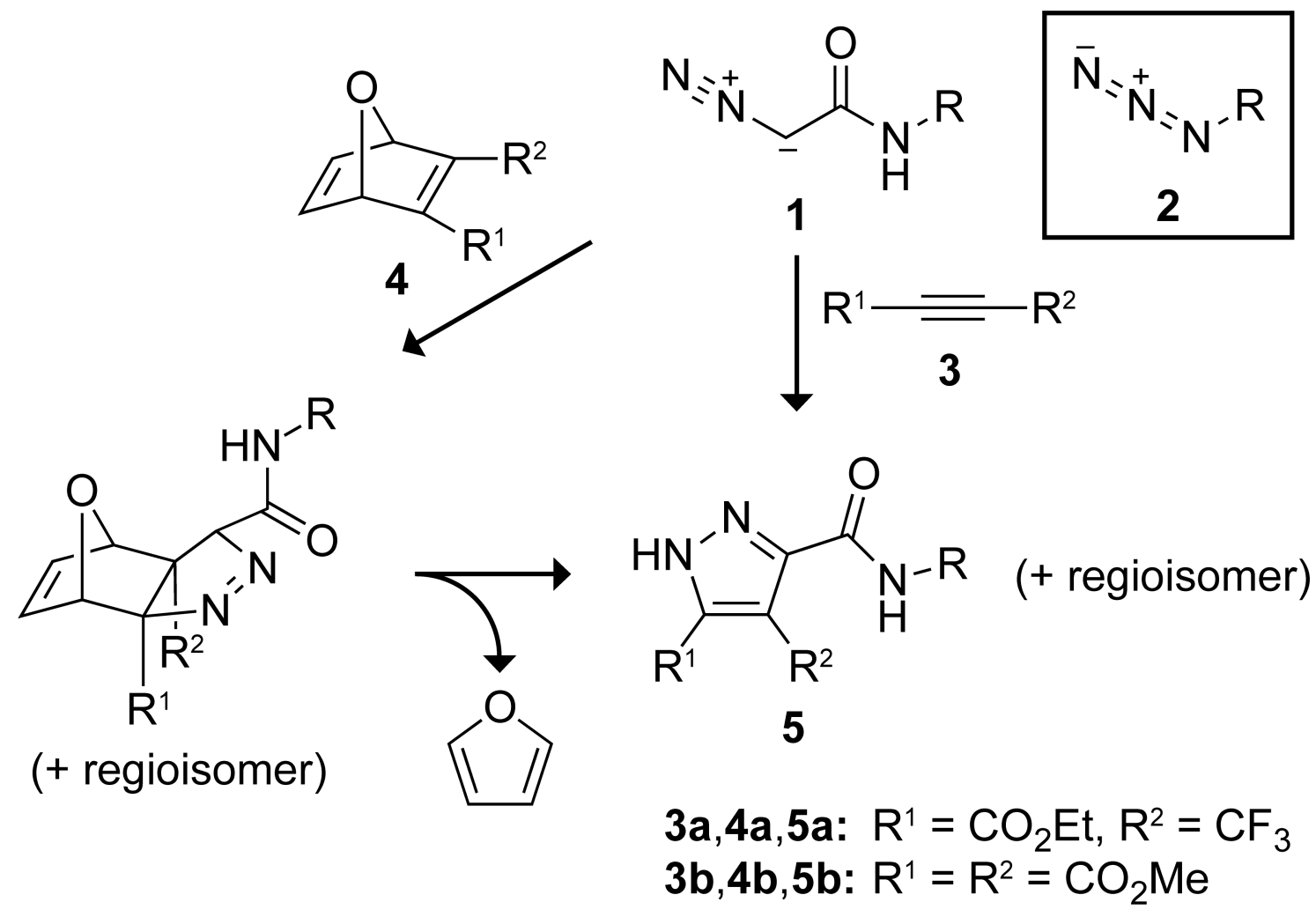

Scheme 1.

Pyrazole product obtained from the 1,3-dipolar cycloaddition of diazoacetamide 1 with alkyne 3 and oxanorbornadiene 4 . Azide 2 reacts analogously to form a triazole. 


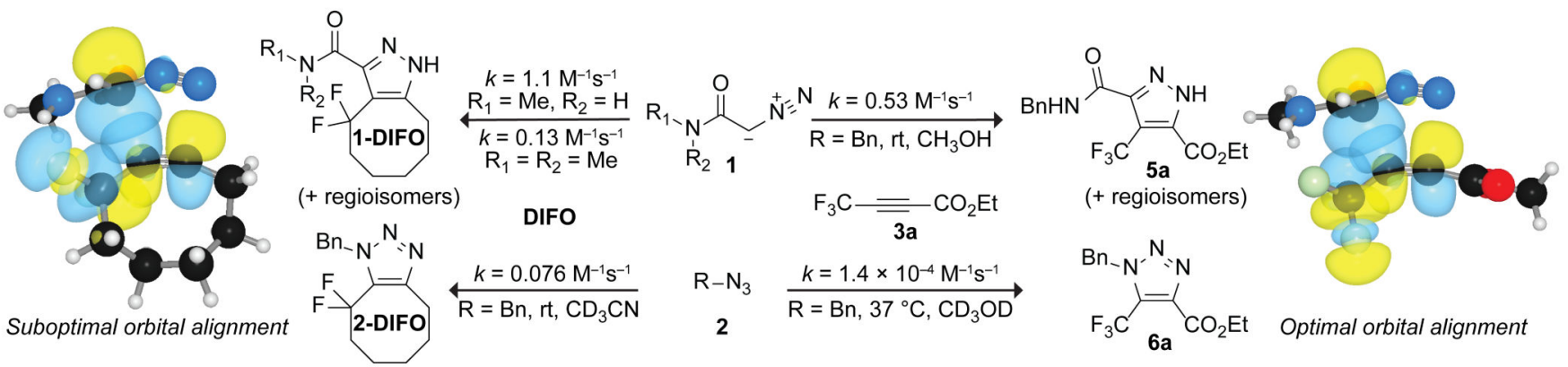

Scheme 2. 


\section{Table 1}

Rate Constants for the Cycloaddition of Diazoacetamide $1(\mathrm{R}=\mathrm{Bn})$ with Alkynes 3a and 3b and with ONDs $4 \mathrm{a}$ and $4 \mathrm{~b}^{\mathrm{a}}$

\begin{tabular}{|c|c|c|c|c|}
\hline dipolarophile & & $\mathbf{R}^{1}$ & $\mathbf{R}^{2}$ & $k\left(10^{-2} \mathrm{M}^{-1} \mathrm{~s}^{-1}\right)^{a}$ \\
\hline & $3 a$ & $\mathrm{CO}_{2} \mathrm{Et}$ & $\mathrm{CF}_{3}$ & 53 \\
\hline \multicolumn{5}{|c|}{$\mathrm{R}^{1}=\mathrm{R}^{2}$} \\
\hline & $3 \mathbf{b}$ & $\mathrm{CO}_{2} \mathrm{Me}$ & $\mathrm{CO}_{2} \mathrm{Me}$ & 0.46 \\
\hline & $4 a$ & $\mathrm{CO}_{2} \mathrm{Et}$ & $\mathrm{CF}_{3}$ & 1.5 \\
\hline & $4 b$ & $\mathrm{CO}_{2} \mathrm{Me}$ & $\mathrm{CO}_{2} \mathrm{Me}$ & 1.1 \\
\hline
\end{tabular}

${ }^{a}$ Values were determined in methanol with ${ }^{1} \mathrm{H}$ NMR spectroscopy or ultraviolet spectroscopy. 


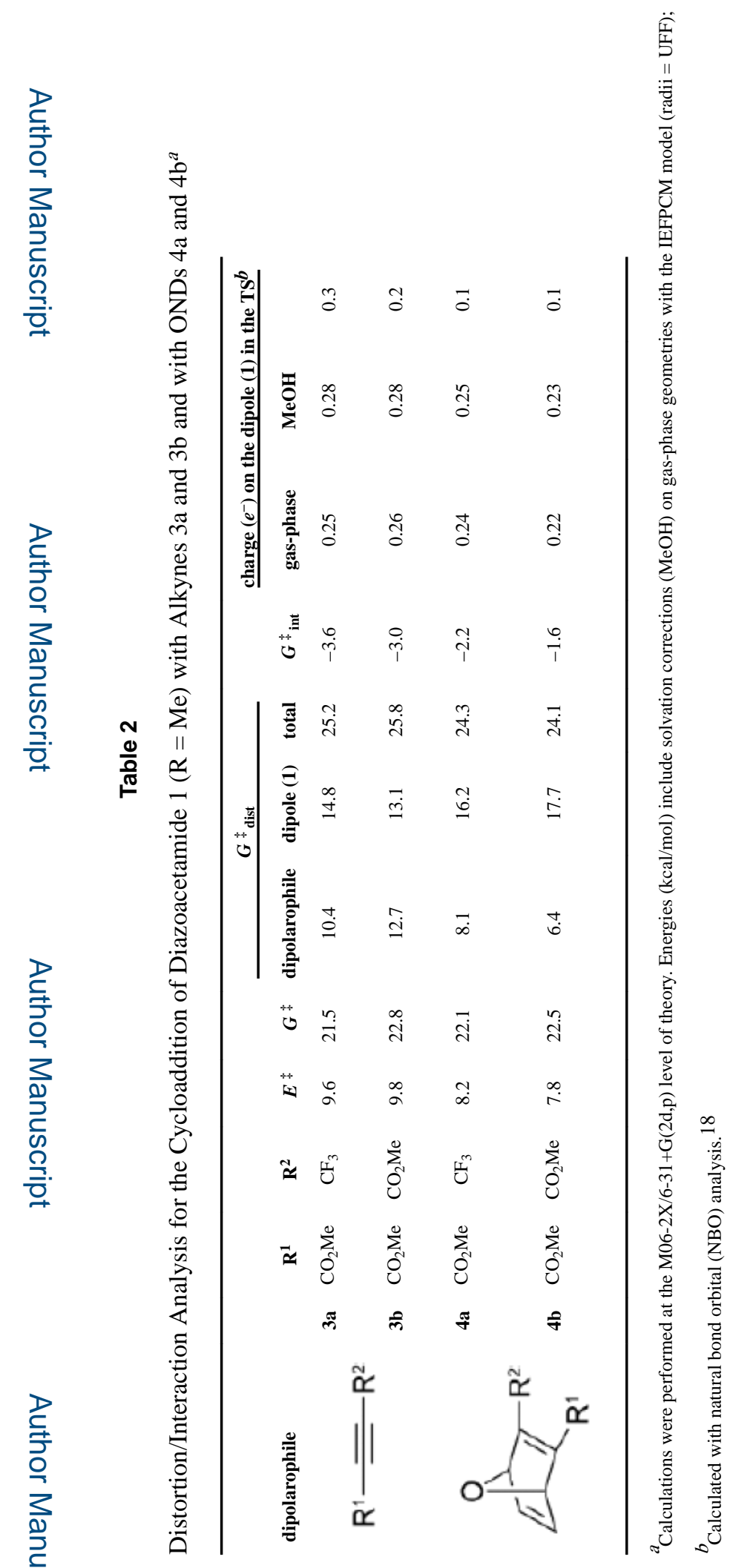

Org Lett. Author manuscript; available in PMC 2016 December 09. 